\title{
In Silico Prediction of Percutaneous Absorption and Disposition Kinetics of Chemicals
}

\author{
Longjian Chen • Lujia Han • Ouarda Saib • Guoping Lian
}

Received: 25 July 2014 / Accepted: 10 November 2014

(C) Springer Science+Business Media New York 2014

\begin{abstract}
Purpose To develop in-silico model for predicting percutaneous absorption and disposition kinetics of chemicals in skin layers so as to facilitate the design of transdermal drug delivery systems and skin care products, and risk assessment of occupational or consumer exposure. Methods A general-purpose computer model for simulating skin permeation, absorption and disposition kinetics in the stratum corneum, viable dermis and dermis has been developed. Equations have been proposed for determining the partition and diffusion properties of chemicals by considering molecular partition, binding and mobility in skin layers. In vitro skin penetration data of 12 chemicals was used to validate the model.

Results The observed and simulated permeation and disposition in skin layers were compared for 12 tested chemicals. For most tested chemicals, the experimental and model results are in good agreement with the coefficient of determination $>0.80$ and relative root mean squared error $<1.20$. The disposition kinetic parameters of the maximum concentration and the area under the curve in the viable epidermis and dermis initially increased with hydrophobicity, but reached maxima and then decreased with further increase of hydrophobicity.

Conclusions By considering skin physiological structure and composition, the partition and diffusion properties of chemicals in skin layers are determined. This allows in-silico simulation of percutaneous permeation, absorption and disposition kinetics of wide chemical space. The model produced results in good agreement with experimental data of 12 chemicals, suggesting a much improved framework to support transdermal delivery of drug and cosmetic actives as well as integrated risk assessment.
\end{abstract}

KEY WORDS diffusion · disposition · model · percutaneous absorption · skin

\section{INTRODUCTION}

Design of transdermal drug delivery systems $(1,2)$ and skin care products (3), and risk assessment of occupational or dermal exposure $(4,5)$ require dermatopharmacokinetic characterization of percutaneous permeation, absorption and disposition kinetic data in different layers of the skin. Due to ethical difficulties and economic considerations with respect to human and animal test, there is an increasing need to develop non-animal approaches. The key starting point for transdermal drug and cosmetic active delivery and safety risk assessment using non-animal approaches is to quantify the absorption and distribution of chemicals in skin layers and other relevant organs under different exposure scenarios $(6,7)$. This can then be correlated to high throughput in-vitro cell assay and outcome pathways. There have been intensive interests in obtaining these fundamental data for topically applied chemicals $(8,9)$.

In silico modeling of transdermal absorption and disposition is a valuable non-animal approach and a number of mathematical models have been reported (10-20) and comprehensively reviewed recently (21-32). These models include Quantitative Structure Permeability Relationships (QSPR) (11, 13, 28), Physiologically Based Pharmacokinetic (PBPK) models
L. Chen $\cdot$ L. Han $(\bowtie)$

College of Engineering, China Agricultural University (East Campus)

P.O. Box 191, 17 Qing-Hua-Dong-Lu, Beijing 100083

People's Republic of China

e-mail: hanlj@cau.edu.cn

L. Han

e-mail: clj1020@cau.edu.cn
O. Saib · G. Lian ( $\triangle)$

Unilever Research Colworth, Colworth Park, Sharnbrook

Bedfordshire MK44 ILQ, UK

e-mail: guoping.lian@unilever.com

G. Lian

Department of Chemical and Process Engineering, University of Surrey Guildford GU2 7XH, UK 
(15-17, 19), and diffusion-based mechanistic models (12, 14, 20, 22). Many in silico models, in particular QSPR models and mechanistic models, are concerned with the prediction of skin permeability of chemicals using molecular descriptors (molecular weight, octanol-water partition coefficient, hydrogen bonding, etc.) and lipid partition-diffusion properties. Models for predicting skin permeability have had various degrees of success $(22,33-35)$. Skin permeability is a key parameter of how fast chemicals are likely to penetrate skin, but this parameter alone does not provide detailed prediction of absorption and disposition kinetics. Few recently reported models proposed the maximum flux $\left(\mathcal{f}_{\text {max }}\right)$ is a much improved parameters for quantifying the penetration potential of chemicals (21). Still such models are limited to steady state conditions without considering the disposition kinetics in skin layers.

In order to obtain the information of chemical disposition in different skin layers, modeling of the kinetics of adsorption, distribution and clearance processes (by metabolism and excretion), or ADME, is required across skin layers. PBPK modeling of chemical absorption and distribution in skin layers normally uses a compartmental ordinary differential equation approach. Many reported PBPK models are not predictive and require many model parameters to be fitted to experimental data. Anissimov and Roberts (2011) reported a two-compartment PBPK model of drug distribution in the dermis and underlying tissues (36). Similar to other PBPK models $(17,18)$, the transport parameters of different compartments were determined by fitting to experimental data. Extrapolation presents a challenge (15). The PBPK model reported by Van der Merwe et al. (16) linked the stratum corneum (SG) compartment properties to the "brick-andmortar" structure, but had limited considerations of the partition and diffusion properties of chemicals in lipid and corneocyte phases. Naegel et al. (2008) and Selzer et al. (2013) presented a diffusion model of drug permeation through the skin, in which the $\mathrm{SC}$ and viable epidermis/ dermis (deeper skin layers, DSL) were respectively characterized by brick-and-mortar structure and homogeneous compartment $(37,38)$. The model parameters such as partition coefficients and diffusion coefficients were determined under steady-state diffusion experiments (39).

The absorption in the viable epidermis and dermis layers play an important role in the percutaneous disposition kinetics (15). Recently, we reported a "brick and mortar" model of transdermal permeation limited to stratum corneum (14). Chemical partition and binding properties are determined by considering molecular interaction with SC composition. This work aims to extend this model (14) to include viable epidermis and dermis. The partition and diffusion properties of chemical are correlated to their interactions with the compositions of cellular lipid, protein and water in viable dermis and dermis. We first demonstrate closed-form simulation of percutaneous permeation, absorption and disposition kinetics of chemicals. We then validate model prediction with published in vitro data of 12 chemicals covering a wide range of physicochemical properties (molecular size, hydrophobicity, and volatility) (15). Finally, we discuss how molecular weight and hydrophobicity of chemicals influence percutaneous disposition kinetics (the maximum concentration, $\mathrm{C}_{\text {max }}$; the area under the curve, $\mathrm{AUC}$ ) of wide chemicals space under finite dose conditions. The effect of chemical volatility on percutaneous permeation, absorption and disposition kinetics has been also discussed. To our knowledge, closed-form simulation of dermatokinetics of absorption and disposition in skin layers with validation of large data sets is the first in its kind and represents a much improved framework of using in-silico prediction to support transdermal delivery of drugs and skincare actives as well as integrated risk assessment of dermal exposure to chemicals.

\section{MATERIALS AND METHOD}

\section{Volatility Experiments of Chemicals}

The volatility experiments of the aformentioned 12 chemicals (1,4-dihydroquinone, benzaldehyde, 3,4-dihydrocoumarin, 4ethylresorcinol, cinnamic aldehyde, 6-methylcoumarin, cinnamyl alcohol, 2,4-dinitrochlorobenzene, phenylbenzoate, $\alpha$-hexylcinnamic aldehyde, 1-bromododecane, and 1bromohexadecane) were executed. The 12 test chemicals cover a wide range of physicochemical properties (MW ranging from 106.13 to $305.35 \mathrm{Da}, \log K_{o w}$ varying from 0.59 to 8.54, Table I) (40, 41). All the tested chemicals, olive oil (highly refined, low acidity), acetone (LC-MS grade), ultra pure water (LC-MS grade), ethanol (LC-MS grade), methanol (LC-MS grade), and dichloromethane (HPLC grade) were supplied by Sigma-Aldrich Company Limited (Gillingham, Kent, UK). The charcoal filters (universal cooker hood filters, UNIFIT) were purchased at a local grocery store.

The conditions for the evaporation test were chosen to closely mimic those in the absorption test in the Davies et al. (15), which also employed charcoal filters over the test samples. Evaporation in this case occurs by free convection rather than the airflow-related mass transfer process experienced on unoccluded sites. For each test chemical a $189 \mathrm{mM}$ dose solution was prepared in the dose vehicle acetone:olive oil (AOO, $4: 1 \mathrm{v} / \mathrm{v})$. A $3 \mathrm{~cm}^{2}$ piece of charcoal filter was placed in the middle of a $10 \mathrm{ml}$ glass vial. The bottom of the vial was carefully spiked with a $33 \mu \mathrm{l}$ aliquot of the $189 \mathrm{mM}$ dose solution (avoiding to contaminate the filter), capped immediately and heated at $32^{\circ} \mathrm{C}$ for a fixed period of time (from $1 \mathrm{~min}$ to $24 \mathrm{~h}$ ). The evaporation profiles of the test chemicals between $\mathrm{AOO}$ and the air under occluded conditions were assessed using various chromatography methods. The headspace was analysed by Headspace Gas Chromatography Mass 
Table I The Properties, Applied Dose, and Evaporated Percentage of I 2 Test Chemicals

\begin{tabular}{|c|c|c|c|c|c|}
\hline Test chemical & MW (Da) & $\log K_{\text {ow }}$ & $\log K_{m}{ }^{d}$ & $\mathrm{C}_{\text {applied }}(\mathrm{mM})^{\mathrm{e}}$ & $M_{e}(\%)^{f}$ \\
\hline I,4-dihydroquinone & $110.1 \mid$ & $0.59^{a}$ & 1.20 & $76 ; 191$ & 0.97 \\
\hline benzaldehyde & 106.13 & $1.48^{a}$ & 2.18 & 191; 2359 & 81.09 \\
\hline 3,4-dihydroucoumarin & 148.16 & $0.97^{b}$ & 1.15 & $191 ; 380$ & 42.21 \\
\hline 4-ethylresorcinol & 138.17 & $2.07^{b}$ & 1.36 & 191; 399 & 0.07 \\
\hline cinnamic aldehyde & 132.16 & $1.90^{\circ}$ & 1.60 & 195 & 39.32 \\
\hline 6-methylcoumarin & 160.17 & $2.06^{b}$ & 1.34 & 203 & 20.35 \\
\hline cinnamyl alcohol & 134.18 & $1.95^{a}$ & 1.62 & $192 ; 1510$ & 10.78 \\
\hline 2,4-dinitrochlorobenzene & 202.55 & $2.17^{c}$ & 1.85 & $99 ; 189$ & 12.72 \\
\hline Phenyl benzoate & 198.22 & $3.59^{\circ}$ & 2.70 & $187 ; 379$ & 11.66 \\
\hline a-hexylcinnamic aldehyde & 216.33 & $4.82^{b}$ & 3.40 & 177 & 13.58 \\
\hline I-bromododecane & 249.24 & $6.58^{b}$ & 4.30 & $189 ; 723$ & 4.34 \\
\hline I-bromohexadecane & 305.35 & $8.54^{b}$ & 5.48 & 189; 379 & 1.4 \\
\hline
\end{tabular}

a Experimental log $K_{\text {ow }}$ value obtained from Hansche et al. (1995)

${ }^{b}$ Predicted log $K_{\text {ow }}$ value obtained from KOWWIN v. $167 \mathrm{a}$

c Experimental logK ow value obtained from Debnath et al. (1991)

${ }^{d} K_{w}$ is the partition coefficient of a chemical between vehicle and water

${ }^{\text {e }} \mathrm{C}_{\text {applied }}$ is the applied concentration of test chemical

${ }^{f} M_{\mathrm{e}}$ is the evaporated percentage of applied dose after $24 \mathrm{~h}$, which is calculated from mass balance of in vitro diffusion data

For the chemicals with different applied concentrations, the average values of $M_{e}$ were calculated

Spectrometry. The vial was then uncapped and the piece of filter removed. An aliquot of $1.5 \mathrm{ml}$ of ethanol was added immediately to the $10 \mathrm{ml}$ glass vial to extract the test chemical remaining in AOO. The extract was analysed by HPLG-UV. The filter was extracted with $5 \mathrm{ml}$ of dichloromethane for a minimum of $8 \mathrm{~h}$. The extracts were filtered (Whatman PTFE syringe filter, $0.45 \mu \mathrm{m}$ ) and analysed by Liquid Injection Gas Chromatography Mass Spectrometry.

A range of calibration standards for each chemical were prepared in AOO for the Headspace Gas Chromatography analysis (from 0.005 to $20 \mathrm{mM}$ ). The test samples were analysed using an Agilent 6890N gas chromatograph system with an Agilent 5973 mass selective detector. The samples were analysed by injecting $750 \mu \mathrm{L}$ of sample or standard in a split mode (100:1 ratio) (for headspace analysis) or $1 \mu \mathrm{L}$ of sample or standard in a splitless mode (liquid injection analysis) onto a J\&W Scientific DB-624 column (30 m*0.32 mm ID, film thickness $1.8 \mu \mathrm{m}$.) The gradient and other conditions are reported in Table II.

A range of calibration standards for each chemical (1Bromododecane and 1-bromohexadecane cannot be detected by UV analysis and were analysed by Liquid Injection Gas Chromatography Mass Spectrometry) were prepared in ethanol (from 5 to $800 \mathrm{ppm}$ ). The samples were analysed using an Agilent 1100 HPLC-UV system with a Multi-wavelength detector. The hydroquinone and phenyl benzoate samples and standards were analysed by injecting a $2 \mu \mathrm{l}$ of sample or standard onto a Phenonmenex Luna phenyl-hexyl column $(100 * 2.00 \mathrm{~mm}, 3 \mu \mathrm{m})$. The other chemical standards and samples were analysed by injecting a $2 \mu \mathrm{l}$ of sample or standard onto a Thermo Hypersil Gold C18 column $(100 * 2.1 \mathrm{~mm}, 3 \mu \mathrm{m})$. Ultra pure water $(\mathrm{A})$ and methanol $(\mathrm{B})$ were used as mobile phases. The gradient and temperature conditions are reported in Table II.

\section{Collection of Skin Absorption Experiment Data}

In vitro human skin penetration data of 12 tested chemicals were obtained from previous experiments described in Davies et al. (2011). The data include monitored time-course of chemical concentrations in both the donor and receptor fluids. Chemical distribution in different layers of the skin was also obtained. All the chemicals were dissolved in the vehicle at a concentration of approximately $189 \mathrm{mM}$. In addition, most chemicals were tested at a concentration of approximately double or half of $189 \mathrm{mM}$. A dose $\left(25 \mu \mathrm{l} / \mathrm{cm}^{2}\right)$ of the vehicle was applied for the donor phase. For each chemical, parallel experiments were performed, terminating at $0.5,1,2,4,8$ and $24 \mathrm{~h}$ respectively. The outliers from parallel experiments were detected by Grubbs test (the significance level is set to $1 \%$ ). The skin samples were tape-stripped ten times. The tapestripped skin was separated into the viable epidermis and dermis by heat treatment. Detailedly, the tape-stripped skin was wrapped in cling film and a 200-g brass weight, heated to $60^{\circ} \mathrm{C}$, was applied for $90 \mathrm{~s}$ to the upper surface of the skin. The skin was then unwrapped and the viable epidermis removed by scraping with forceps. The amount of radio labelled chemicals in each skin layers as well as in the receptor fluid was 
Table II Gas Chromatography Mass Spectrometry and HPLC UV Conditions

\begin{tabular}{|c|c|c|c|c|c|c|c|c|c|c|}
\hline \multirow[t]{2}{*}{ Test chemical } & \multicolumn{6}{|c|}{ GC-MS conditions } & \multicolumn{4}{|c|}{ HPLC UV conditions } \\
\hline & $\begin{array}{l}\text { Flow rate } \\
\left({ }^{\circ} \mathrm{C} / \mathrm{min}\right)\end{array}$ & $\begin{array}{l}\text { Initial } \\
\text { temperature } \\
\left({ }^{\circ} \mathrm{C}\right)\end{array}$ & $\begin{array}{l}\text { Final } \\
\text { temperature } \\
\left({ }^{\circ} \mathrm{C}\right)\end{array}$ & $\begin{array}{l}\text { Total run } \\
\text { time (min) }\end{array}$ & $\mathrm{m} / \mathrm{z}$ & $\begin{array}{l}\text { Flow rate } \\
(\mathrm{ml} / \mathrm{min})\end{array}$ & $\begin{array}{l}\text { Temperature } \\
\left({ }^{\circ} \mathrm{C}\right)\end{array}$ & $\begin{array}{l}\text { Gradient } \\
\text { conditions }\end{array}$ & $\begin{array}{l}\text { Total run } \\
\text { time (min) }\end{array}$ & $\begin{array}{l}\text { Wave } \\
\text { length } \\
(\mathrm{nm})\end{array}$ \\
\hline I,4-dihydroquinone & 35 & 160 & 230 & 9 & 110 & 0.28 & 30 & $\begin{array}{r}90 / 10 \mathrm{~A} / \mathrm{B} \text { to } \\
10 / 90 \mathrm{~A} / \mathrm{B}\end{array}$ & 16 & 225 \\
\hline benzaldehyde & 20 & 160 & 185 & 6 & 106 & 0.3 & 35 & $\begin{array}{r}60 / 40 \mathrm{~A} / \mathrm{B} \text { to } \\
10 / 90 \mathrm{~A} / \mathrm{B}\end{array}$ & 14 & 204 \\
\hline 3,4-dihydrocoumarin & 32 & 180 & 230 & 10.56 & 148 & 0.25 & 30 & $\begin{array}{r}50 / 50 \mathrm{~A} / \mathrm{B} \text { to } \\
10 / 90 \mathrm{~A} / \mathrm{B}\end{array}$ & 14.5 & 203 \\
\hline 4-ethylresorcinol & 25 & 150 & 230 & 10.2 & 123 & 0.25 & 30 & $\begin{array}{r}50 / 50 \mathrm{~A} / \mathrm{B} \text { to } \\
10 / 90 \mathrm{~A} / \mathrm{B}\end{array}$ & 14.5 & 203 \\
\hline cinnamic aldehyde & 30 & 145 & 230 & 10.17 & 131 & 0.3 & 30 & $\begin{array}{r}50 / 50 \mathrm{~A} / \mathrm{B} \text { to } \\
10 / 90 \mathrm{~A} / \mathrm{B}\end{array}$ & 14.5 & 285 \\
\hline 6-methylcoumarin & 30 & 135 & 230 & 6.12 & 160 & 0.25 & 30 & $\begin{array}{r}50 / 50 \mathrm{~A} / \mathrm{B} \text { to } \\
10 / 90 \mathrm{~A} / \mathrm{B}\end{array}$ & 14.5 & 203 \\
\hline cinnamic alcohol & 30 & 132 & 230 & 7.33 & 92 & 0.25 & 30 & $\begin{array}{r}50 / 50 \mathrm{~A} / \mathrm{B} \text { to } \\
10 / 90 \mathrm{~A} / \mathrm{B}\end{array}$ & 14.5 & 209 \\
\hline 2,4-dinitrochlorobenzene & 35 & 180 & 230 & 10 & 202 & 0.25 & 30 & $\begin{array}{r}50 / 50 \mathrm{~A} / \mathrm{B} \text { to } \\
10 / 90 \mathrm{~A} / \mathrm{B}\end{array}$ & 14.5 & 203 \\
\hline phenylbenzoate & 35 & 185 & 230 & 9.49 & 105 & 0.3 & 30 & $\begin{array}{r}30 / 70 \mathrm{~A} / \mathrm{B} \text { to } \\
10 / 90 \mathrm{~A} / \mathrm{B}\end{array}$ & 16 & 201 \\
\hline a-hexylcinnamic aldehyde & 35 & 180 & 230 & 10.43 & 129 & 0.3 & 45 & $\begin{array}{r}60 / 40 \mathrm{~A} / \mathrm{B} \text { to } \\
10 / 90 \mathrm{~A} / \mathrm{B}\end{array}$ & 16 & 282 \\
\hline I-bromododecane & 30 & 190 & 230 & 6.62 & 137 & - & - & - & - & - \\
\hline I-bromohexadecane & - & 245 & 245 & 11.3 & $|35 ; 7|$ & - & - & - & - & - \\
\hline
\end{tabular}

measured by liquid scintillation counting. The mass balance of the measured chemical compounds in the donor fluid, receptor fluid and skin were checked at different time of the experiments. Further details on experimental materials and methods were described in Davies et al. (2011).

\section{Model Description}

Figure 1 represents the schematic framework for modelling transdermal absorption and disposition under the flowthrough diffusion cell set-up. The process is simulated as a process consisting of 1) penetration of tested chemical from the vehicle into the $\mathrm{SC}, 2$ ) diffusion and accumulation in the $\mathrm{SC}$, 3) penetration into the viable epidermis, 4) diffusion and accumulation in the dermis and release to a 'sink'. Due to high volatility of acetone, the vehicle was assumed to be consisted of only olive oil by taking into account that acetone was fully evaporated at the very early stage of the in-vitro experiment. After the evaporation of acetone, the initial concentration and thickness of vehicle respectively changed according to the vehicle composition (acetone:olive oil, 4:1 v/v). The vehicle thickness was set to $50 \mu \mathrm{m}$, derived from the evaporated volume and area of the donor. The interaction of acetone with skin lipid has not been modeled in this study. The geometrical and compositional parameters of the SC were set to the same as reported in a previous study (14).
The number of the SC corneocyte layers is set to 12 and the corresponding SC thickness is $10.5 \mu \mathrm{m}$ with the typical size of the $\mathrm{SC}$ corneocyte cell. The thicknesses of the viable epidermis and dermis were set to 100 and $1200 \mu \mathrm{m}(42,43)$ respectively, comparable to the values reported by Pendlington et al. (2008). Both the viable epidermis and dermis layers were simulated as multiphase materials consisting of $65 \%$ water, $2.5 \%$ lipids and $32.5 \%$ proteins which are typical values quoted in the literature $(23,44)$. The thickness of the receptor fluid was set to $4000 \mu \mathrm{m}$ according to the dimension of the receptor fluid.

The viscosity of vehicle (olive oil) at $32^{\circ} \mathrm{C}$ was set to $0.051 \mathrm{~Pa} \cdot \mathrm{s}$ (45), allowing for the calculation of the diffusion coefficient of chemicals in the vehicle using the Stokes-Einstein equation (46). The partition coefficient of a chemical between vehicle and water $\left(K_{v w}\right)$ is an important parameter affecting transdermal permeation. The partition property of chemicals in olive oil is not readily available. In this study, this is the only parameter initially estimated from the measured buildup of chemicals in the SC and further refined by fitting the predicted percentages of applied dose in the skin layers to the observed values. It is very interesting to note that the fitted $K_{v w}$ values of the tested chemicals have good power-law correlation with the octanol-water partition coefficient $K_{\text {ow }}\left(K_{v w}=4.62 K_{\text {ow }}{ }^{0.55}\right)$ (Table I and Fig. 2). This is not surprising as one would expect hydrophobicity as an important factor affecting solute partition in olive oil. 
Fig. I Overall scheme and element discretization for modelling transdermal penetration and absorption under in vitro conditions.

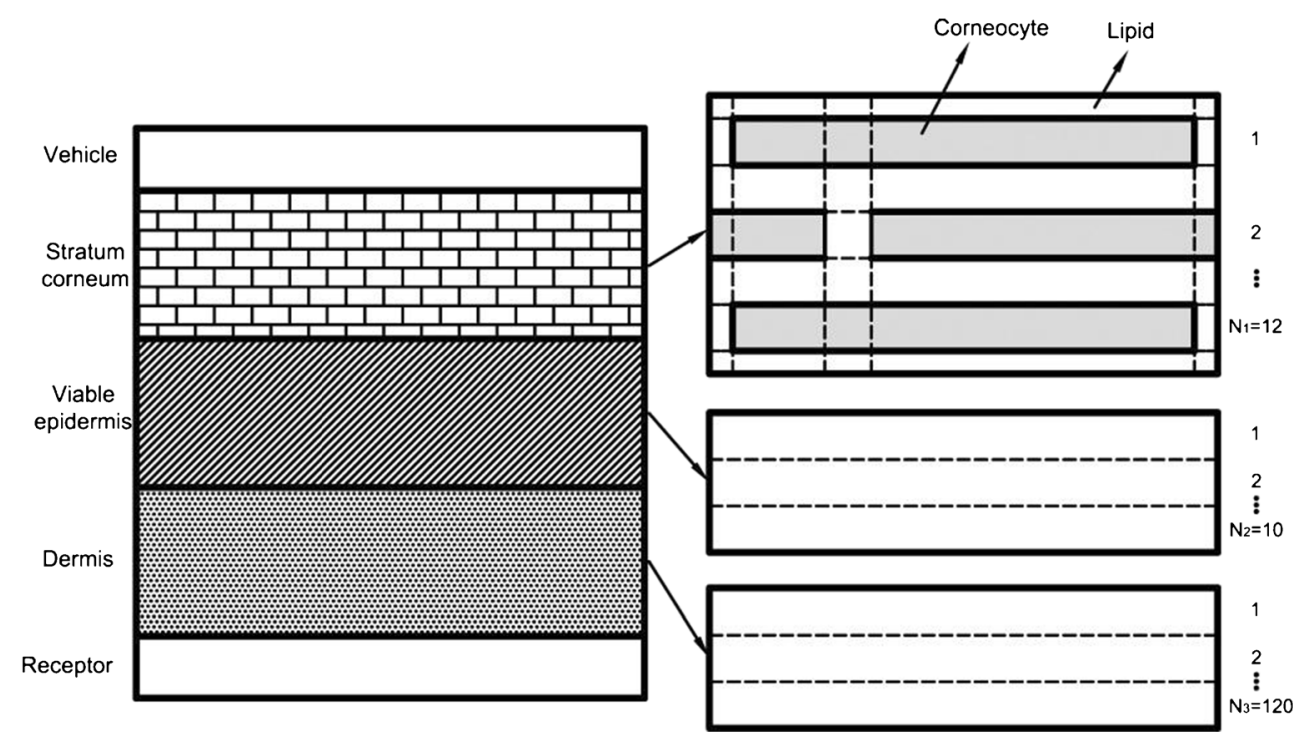

The SC is modelled by the so-called "brick and mortar" we reported recently. Detailed description of the model can be found in the original article (14). Here, for completeness, a brief summary is given. The solute partition coefficient between vehicle and SC lipid $\left(K_{v m}\right)$ is derived from the chain rule

$\kappa_{v m}=\frac{K_{v w}}{K_{m w}}$

where $K_{m w}$ is solute partition coefficient of SC lipid to water and can be determined by the following reported correlation relationship with octanol-water partition property:

$K_{m w}=\frac{\rho_{l}}{\rho_{w}} K_{o w}^{0.69}$

where $\rho_{l}\left(=0.9 \mathrm{~g} / \mathrm{cm}^{3}\right)$ and $\rho_{w}\left(=1 \mathrm{~g} / \mathrm{cm}^{3}\right)$ represent the bulk density of lipid and water $(47,48)$.

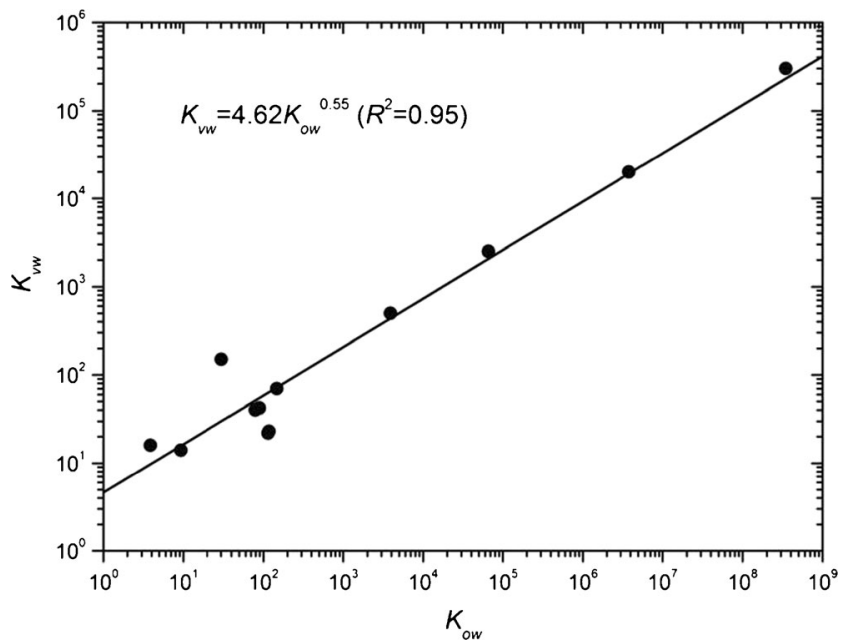

Fig. 2 The relationship between $K_{w}$ and $K_{\text {ow }}$ for 12 tested chemicals. The line corresponds to the fitted equation $\left(K_{w w}=4.62 K_{o w}{ }^{0.55}\right)$ between $K_{w}$ and $K_{\text {ow }}$ for 12 tested chemicals.
Solute partition coefficient of SC corneocytes to water $\left(K_{b w}\right)$ is estimated from the following equation (14):

$K_{b w}=\left(1-\varphi_{b}\right) K_{k w}+\theta_{b}$

where $\phi_{b}$ is the volume fraction of water at saturation and $\theta_{b}$ is the actual volume fraction of water in the corneocyte phase, $K_{k w}$ is the solute binding constant to SC keratin and is determined by the following reported correlation (48):

$K_{k w}=\frac{\rho_{k}}{\rho_{w}} 4.2 K_{o w}^{0.31}$

where $\rho_{k}\left(=1.37 \mathrm{~g} / \mathrm{cm}^{3}\right)$ represents the bulk density of keratin $(47,48)$.

Solute diffusion coefficient in the SC lipid is related to solute radius $\left(r_{s}\right)$ by the equation proposed by Mitragotri (12, 49):

$D_{m}\left(\mathrm{~m}^{2} / \mathrm{s}\right)=\left\{\begin{array}{ccc}2 \times 10^{-9} \exp \left(-0.46 r_{s}^{2}\right) & \text { if } & M W \leq 380 \mathrm{Da} \\ 3 \times 10^{-13} & \text { if } & M W>380 \mathrm{Da}\end{array}\right.$

Solute diffusion coefficient in the SC corneocyte $\left(D_{b}\right)$ is estimated from our recent study $(14,49)$ :

$\frac{D_{b}}{D_{w}}=\frac{\exp \left[-\alpha S^{\lambda}\right]}{\left[1+\frac{r_{s}}{\sqrt{k}}+\frac{r_{s}^{2}}{3 k}\right]}$

where:

$k=\beta r_{f}^{2}\left(1-\theta_{b}\right)^{\gamma}$

$S=\left(1-\theta_{b}\right)\left(\frac{r_{s}+r_{f}}{r_{f}}\right)^{2}$ 
where $D_{w}$ is the diffusion coefficient of solute in free water and can be predicted using the Stokes-Einstein equation (46), $k$ is the hydraulic permeability and is estimated from the correlation derived by Jackson and James (50), $r_{f}$ is the radius of keratin microfibril $\left(r_{f}=35 \AA\right)(51), \alpha, \lambda, \beta$ and $\gamma$ are model parameters and their values are set to $\lambda=1.09, \gamma=-1.17, \alpha=$ 9.47 and $\beta=9.32 \times 10^{-8}(49)$.

Literature suggests that viable epidermis and dermis have similar multiphase compositions $(23,44)$. For this reason, the partition and diffusion properties in the two layers can be assumed to be similar, which was also applied in previous studies $(23,52)$. Chemicals present in the viable epidermis and dermis are much more mobile compared to that in the $\mathrm{SC}$. Because of the multiphase nature of the viable epidermis and dermis, a chemical in these skin layers will have complex interactions different from water. One of the important interactions is the binding to proteins, which leads to a partition between dermis and water. Some models have been proposed for the partition coefficient between dermis and water, $K_{\text {dew }}$, $(44,53)$. For example, Bunge \& Cleek (1995) related $K_{\text {dew }}$ to $K_{\text {ow }}$ based on linear free energy theory and proposed the following equation:

$K_{\text {dew }}=K_{\text {ow }}^{0.38}$

The above model is for the bulk property and did not consider the multiphase nature of the viable dermis and dermis. Kretsos et al. (2008) and Ibrahim et al. (2012) considered the composition of skin dermis and proposed the following equation assuming that solutes were excluded from the collagen and elastin protein region:

$K_{\text {dew }}=0.7 \times\left(0.68+\frac{0.32}{f_{u}}+0.001 f_{\text {non }} K_{\text {ow }}\right)$

Where $f_{\text {non }}$ is the nonionized fraction of solute in the aqueous phase, $f_{u}$ is the fraction of unbound (to albumin) solute which can be calculated from the equation described by Yamazaki and Kanaoka (54). It should be noted that current $f_{u}$ model only considered the binding of albumin protein.

The three terms of $0.68,0.32 / f_{u}$ and $0.001 f_{n o n} K_{o w}$ account for the chemical disposition in albumin-accessible aqueous phase, albumin-inaccessible aqueous phase and lipid phase, respectively. The direct use $K_{\text {ow }}$ in lipid phase overestimates the partition of solute between lipid and water $\left(K_{m w}\right)$ which was often power-law related to $K_{o w}$ based on the observed data of $\mathrm{SC}$ lipid. Although the lipid in viable epidermis and dermis may be chemically different from SC lipid, the Eq. (2) of $K_{m w}$ was still adopted to a first approximation due to the lack of the partition data on the lipid in viable epidermis and dermis. Secondly, the coefficient of 0.001 in $0.001 f_{\text {non }} K_{\text {ow }}$ term underestimates the lipid content of dermis $(\sim 2.5 \%)$. In this study, the Ibrahim model is modified by considering improved estimation of the lipid content and partition property in the dermis as follows:

$K_{\text {dew }}=0.7 \times\left(0.68+\frac{0.32}{f_{u}}+0.025 f_{\text {non }} K_{\text {mw }}\right)$

Another key parameter for modeling solute permeation and distribution in the viable epidermis and dermis is the diffusion coefficient. Molecular mobility in the viable epidermis and dermis is much higher than that in the SC but will be still restricted by the complex structures. Diffusion in the viable epidermis and dermis can take either a transmembrane pathway or inter-cellular pathway. Few models have been reported on the effective diffusion coefficient of chemicals in dermis $\left(D_{d e}\right)$. Bunge \& Cleek (1995) derived the following model:

$D_{d e}\left(\mathrm{~m}^{2} / \mathrm{s}\right)=\frac{7.1 \times 10^{-10}}{M W^{0.5}}$

Considering the combined effect of binding and disposition in water, lipid and protein phases, Kretsos et al. (2008) derived the following effective diffusivity of solutes in the dermis layer as follows:

$D_{d e}\left(\mathrm{~m}^{2} / \mathrm{s}\right)=\frac{D_{\text {free }}}{B_{f}}$

where $D_{\text {free }}$ is the diffusivity in the absence of binding or partitioning and is related to $M W$ by empirical equation $D_{\text {free }}=10^{-8.15-0.655 \log (M W)}, B_{f}$ is the binding factor related to the binding or partitioning properties of the dermis:

$B_{f}=0.68+\frac{0.32}{f_{u}}+0.001 f_{n o n} K_{o w}$

Similar to $K_{\text {dew }}$, we propose to modified Kretsos model as follows:

$D_{d e}\left(\mathrm{~m}^{2} / \mathrm{s}\right)=\frac{10^{-8.15-0.655 \log (M W)}}{0.68+\frac{0.32}{f_{u}}+0.025 K_{m w}}$

The mass transfer equations are solved by a finite difference scheme. Such numerical solution is realized by dividing the skin into finite number of smaller elements. The numerical 
scheme for the mass transfer between neighboring elements $A$ and $B$ can be formulated using the interfacial mass transfer equation:

$q_{A B}=\frac{A_{i}}{\frac{\delta_{A}}{D_{A}}+\frac{K_{A B} \delta_{B}}{D_{B}}}\left(C_{A}-K_{A B} C_{B}\right)$

where $q_{A B}$ is the flux of solute from element $A$ to its neighboring element $B, A_{i}$ is the interfacial area between element $A$ and element $B, \delta_{A}$ and $\delta_{B}$ are the corresponding diffusion length, $D_{A}$ and $D_{B}$ are the diffusion coefficients of element $A$ and $B, C_{A}$ and $C_{B}$ are the solute concentrations in element $A$ and $B, K_{A B}$ is the solute partition coefficient between element $A$ and $B$. There are two cases for the determination of $K_{A B}$ including $K_{A B}=1$ if elements $A$ and $B$ are the same material, $K_{A B}=K_{A w}$ l $K_{B w}$ if element $A$ is different from element $B$. The first case represents mass transfer in vehicle, lipid, corneocyte, viable epidermis, or dermis. The latter case represents solute transfer across vehicle-lipid, lipid-corneocyte, lipid-viable epidermis, viable epidermis-dermis, and dermis-receptor interface.

The above extended model is implemented in MATLAB (The MathWorks Inc., Massachusetts, USA). The elements used for numerical solution in the $\mathrm{SC}$ is the same as that in the Chen et al. (2008), where the total number of elements is $10 \times($ the number of SC corneocyte layer) +5 . The elements in the epidermis and dermis are equally discretized into $10 \mu \mathrm{m}$ thickness element (Fig. 1). According to mass conservation principles, concentration of each element A satisfies the following equation

$\frac{d C_{A}}{d t_{s}}=-\frac{\sum_{B} q_{A B}}{V}$

where $C_{A}$ is the solute concentration in element $A, V$ is the element volume, $t_{s}$ is time, $q_{A B}$ is the flux of solute into/out of element $A$ from neighboring element $B$. A set of ODEs for all elements are assembled using Eq. (17) and solved using MATLAB solver ode $15 \mathrm{~s}$ with variable time steps and specified relative tolerance $\left(\right.$ RelTol) of $1 \times 10^{-3}$.

There are two main input parameters of model: molecular weight and octanol-water partition coefficient of modeled chemicals. Other input parameters are related to the composition and geometrical parameters of the skin and are listed in Table III. The geometry and composition of skin are set to typical values reported in literatures. Another important input parameter is vehicle (olive oil)-water partition coefficient which was derived by fitting to experimental data. We late demonstrate the fitted olive oil-water partition coefficient correlates well with octanol-water partition coefficient. Generally speaking, vehicle-water partition coefficient depends
Table III The Input Parameters of Model

\begin{tabular}{|c|c|c|}
\hline Part name & Parameter & Value \\
\hline \multirow[t]{4}{*}{ Test chemical } & Molecular weight (MW) & See Table I \\
\hline & Octanol-water partition coefficient $\left(K_{\text {ow }}\right)$ & See Table I \\
\hline & Vehicle-water partition coefficient $\left(K_{w}\right)$ & See Table I \\
\hline & Applied concentration ( $\left.C_{\text {applied }}\right)$ & See Table I \\
\hline \multirow[t]{2}{*}{ Vehicle } & Thickness of vehicle & $50 \mu \mathrm{m}$ \\
\hline & Viscosity of vehicle & $0.05 \mathrm{IPa} \cdot \mathrm{s}$ \\
\hline \multirow[t]{14}{*}{ Stratum corneum } & Layers of corneocytes & 12 \\
\hline & Width of corneocytes & $40 \mu \mathrm{m}$ \\
\hline & Heigh of corneocytes & $0.8 \mu \mathrm{m}$ \\
\hline & Thickness of inter-cellular lipid & $0.075 \mu \mathrm{m}$ \\
\hline & The lateral spacing between keratinocytes & $0.075 \mu \mathrm{m}$ \\
\hline & The offset ratio & 8 \\
\hline & Dry mass fraction of lipid & $12.5 \%(w / w)$ \\
\hline & Dry mass fraction of keratin & $87.5 \%(w / w)$ \\
\hline & Saturated water content of the SC & $55 \%(w / w)$ \\
\hline & Water content of the first layer corneocyte & $55 \%(w / w)$ \\
\hline & Water content in the Nth layer corneocyte & $55 \%(w / w)$ \\
\hline & Density of water & $1000 \mathrm{~kg} / \mathrm{m}^{3}$ \\
\hline & Density of lipid & $900 \mathrm{~kg} / \mathrm{m}^{3}$ \\
\hline & Density of keratin & $1370 \mathrm{~kg} / \mathrm{m}^{3}$ \\
\hline \multirow[t]{4}{*}{ Viable epidermis } & Thickness of viable epidermis & $100 \mu \mathrm{m}$ \\
\hline & Mass fraction of water & $65 \%(w / W)$ \\
\hline & Mass fraction of keratin & $32.5 \%(w / w)$ \\
\hline & Mass fraction of lipid & $2.5 \%(w / w)$ \\
\hline \multirow[t]{4}{*}{ Dermis } & Thickness of dermis & $1200 \mu \mathrm{m}$ \\
\hline & Mass fraction of water & $65 \%(w / W)$ \\
\hline & Mass fraction of keratin & $32.5 \%(w / w)$ \\
\hline & Mass fraction of lipid & $2.5 \%(w / w)$ \\
\hline Receptor & Thickness of receptor & $4000 \mu \mathrm{m}$ \\
\hline
\end{tabular}

very much on the formulation of the vehicle and can be experimentally measured or theoretically predicted by considering the solubility of chemicals in the formulation. This is beyond the scope of this study.

\section{RESULTS}

\section{Evaporation Loss of Tested Chemicals}

The mass balance of the measured chemical compounds in the donor fluid, receptor fluid and skin were checked at different time of the experiments. For some chemicals, the total mass from the donor fluid, receptor fluid, skin sample, and diffusion cell are balanced. For other chemicals, the total mass decreased with increasing time and this uncovered mass correlated to the volatility of the chemical. Thus, it was 
thought reasonable to attribute the uncovered mass to evaporative loss of volatiles. Based on the independent evaporation experiment, benzaldehyde and cinnamic aldehyde are highly volatile (the evaporated percentage of applied dose after $24 \mathrm{~h}$ $>60 \%$ ) whilst other chemicals have low volatility or no volatility (the evaporated percentage of applied dose after $24 \mathrm{~h}$ $<15 \%$ ). Except 3,4-dihydrocoumarin and 6-methylcoumarin, the evaporation loss calculated from mass balance of in vitro diffusion data (Table I) and independent evaporation data (Fig. 3) for all other tested chemicals are highly correlated.

With the simulation, the percentage of applied dose evaporated along with diffusion time $\left(M_{\ell}, \%\right)$ for the two highly volatile chemicals is described by the following equation:

$M_{e t}(\%)=M_{e}\left(1-e^{-k t}\right)$

where $k$ is rate constant and is derived from mass balance of the in vitro diffusion data, $t$ is the diffusion time, $M_{e}$ is the evaporated percentage of applied dose after $24 \mathrm{~h}$.

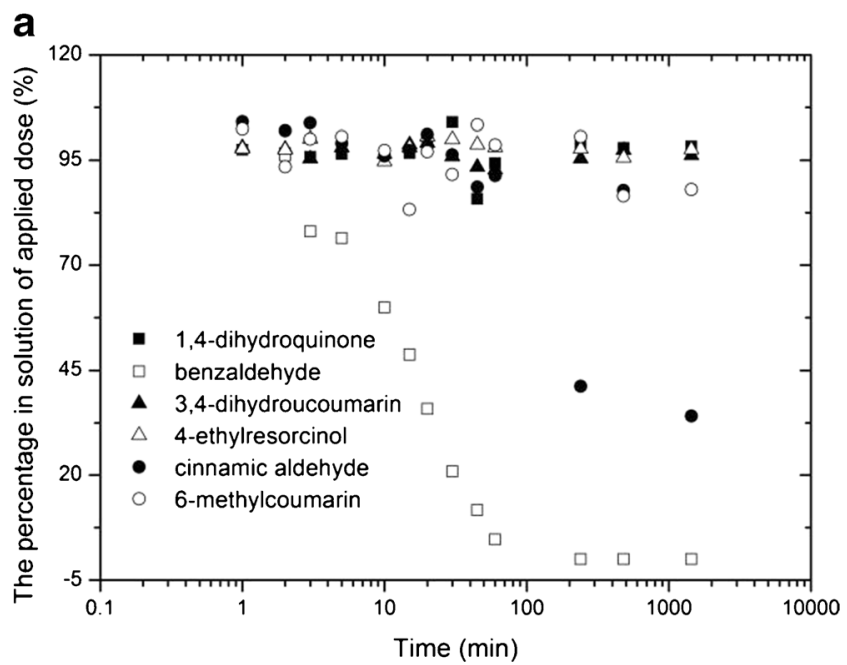

b

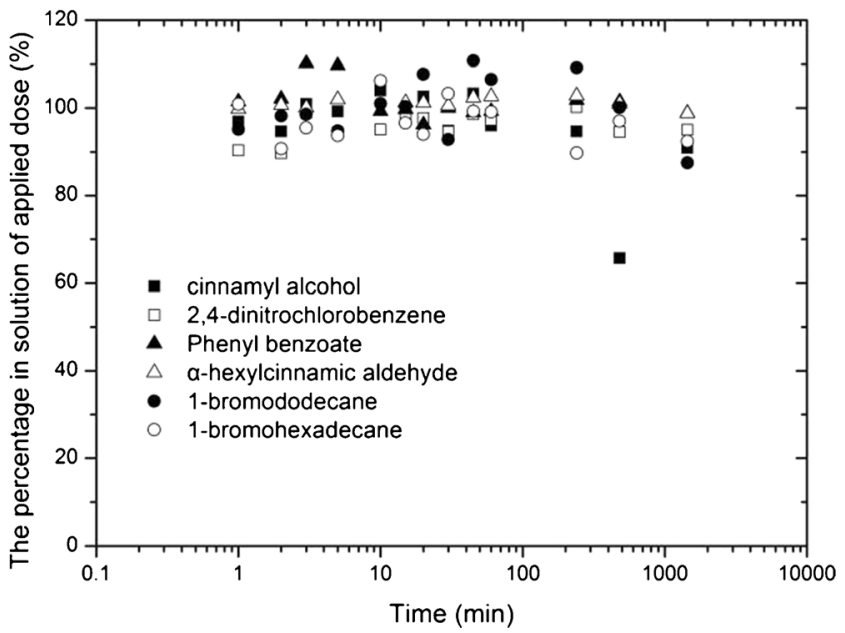

Fig. 3 The percentage in solution of applied dose (\%) along with time in volatility experiments for 12 tested chemicals.
For volatile compound, the concentration in the donor compartment $\left(C_{V}\right)$ can be derived from the mass balance principles by combining Eqs. (17) and (18) as follows

$\frac{d C_{V}}{d t_{s}}=-\frac{\sum_{B} q_{A B}}{V_{V}}-\frac{d M_{e t}}{d t_{s}} \times C_{0} \times 0.01$

where $V_{V}$ is the volume of vehicle, $C_{0}$ is the initial concentration of vehicle.

The $k$ values for benzaldehyde and cinnamic aldehyde were $7.53 \times 10^{-5}$ and $5.21 \times 10^{-5} \mathrm{~s}^{-1}$, respectively. Results of benzaldehyde evaporation loss from independent evaporation data and mass balance of in vitro diffusion data were plotted in Fig. 4. From this it can be determined that the two sets of data are similar in trend and that a large proportion of benzaldehyde is evaporated during the in vitro diffusion experiment. Dancik
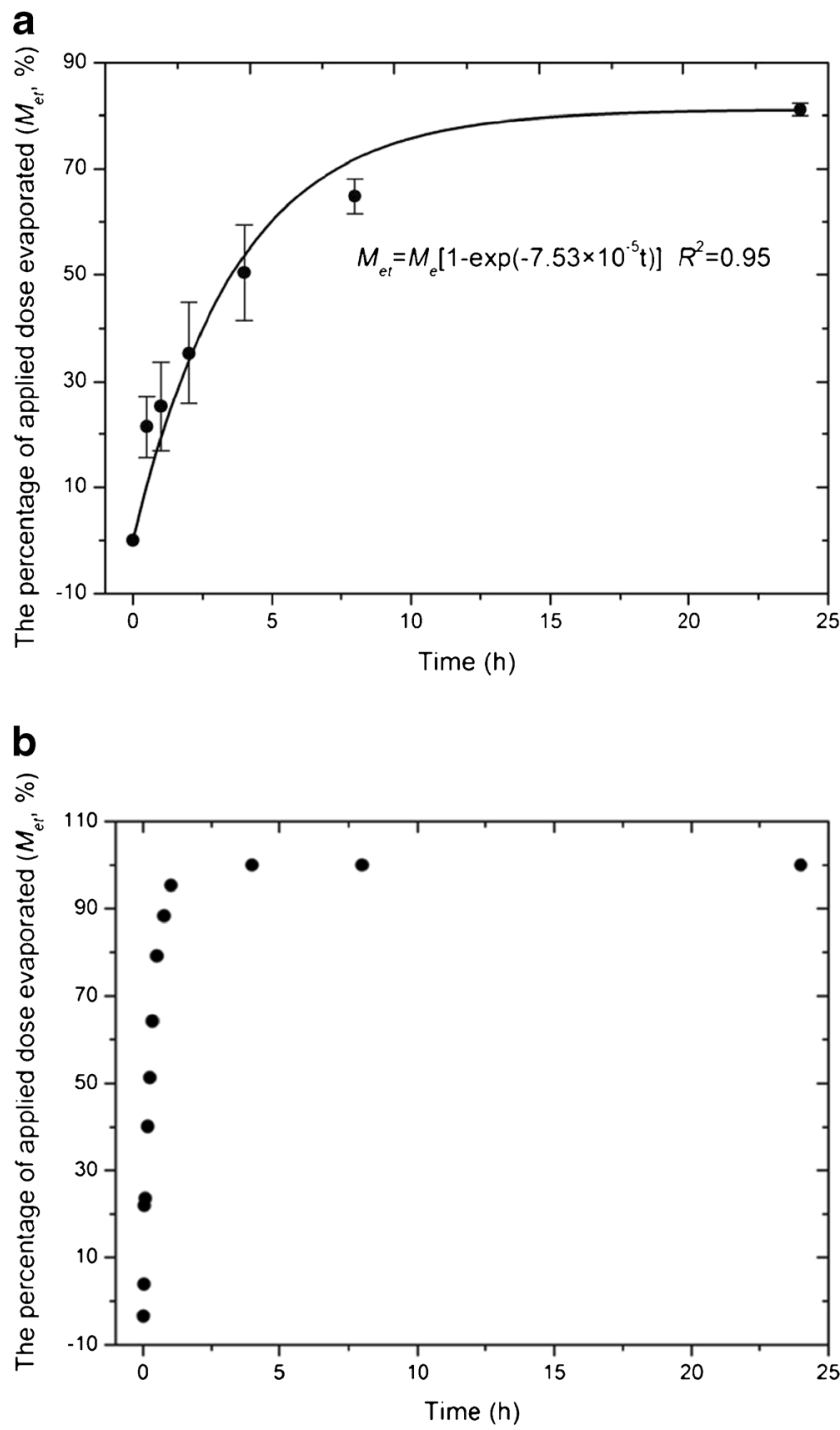

Fig. 4 The evaporated benzaldehyde percentage of applied dose $\left(M_{\mathrm{et}}, \%\right)$ along with the time from (a) mass balance of diffusion data and $(\mathbf{b})$ independent evaporated data. 
et al. (2013) and Gong et al. (2014) proposed empirical correlations for estimating evaporative mass transfer coefficient (23,

a

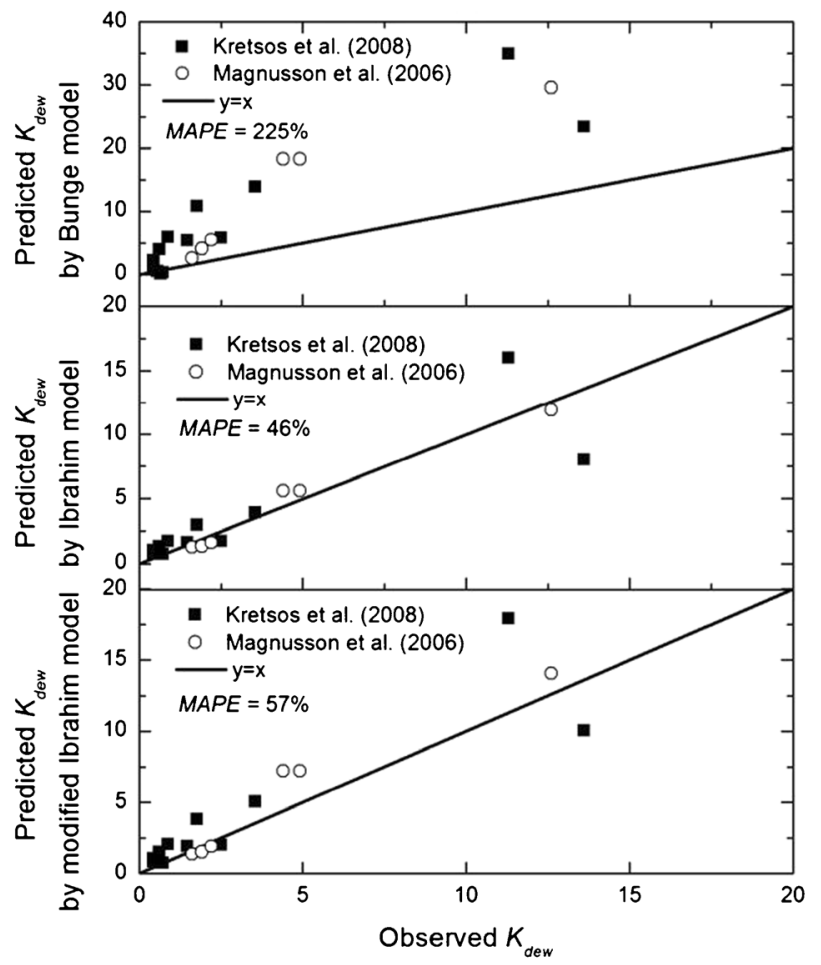

b

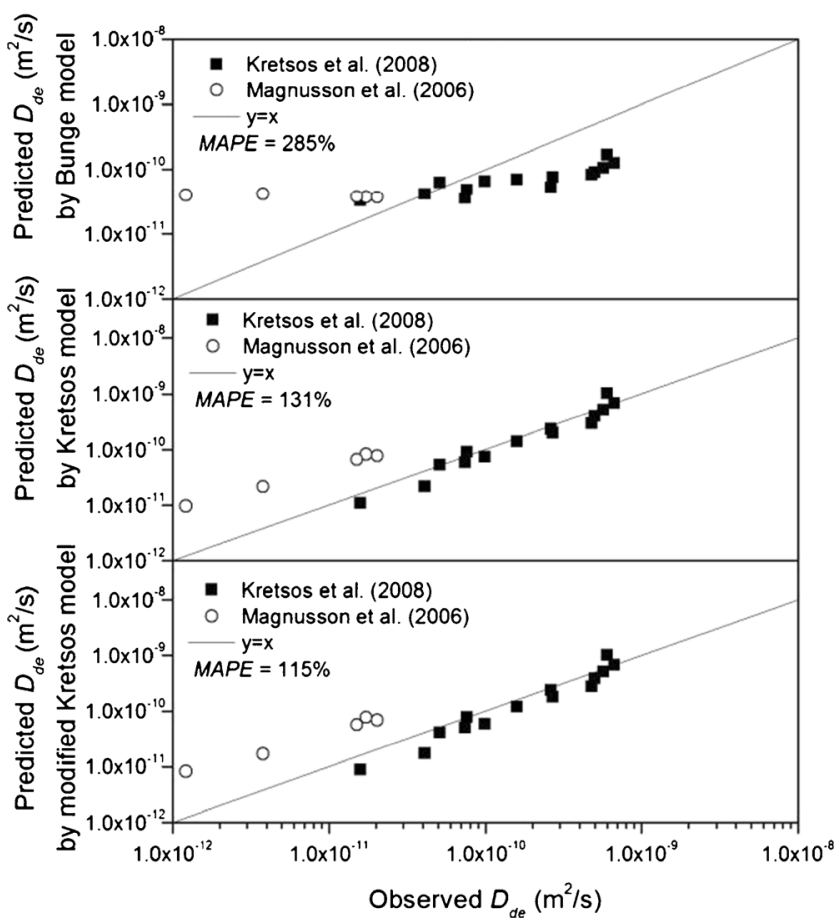

Fig. 5 The comparison of observed (Kretsos et al. (2008) (-) (44); Magnusson et al. (2006) (०) (57)) and predicted (a) dermis-water partition coefficient $\left(K_{\text {dew }}\right)$ and $(\mathbf{b})$ diffusion coefficient in the dermis $\left(D_{\text {de }}\right)$ data by different models $(44,53,58)$.
55), whereas Frasch et al. (2014) developed a dimensionless evaporation number for quantifying the mass balance between applied load and depletion through evaporation (56). Those models require airflow-related mass transfer properties determined. The approach is very similar to this study.

\section{Partition and Diffusion Coefficients of Viable Epidermis and Dermis}

Observed partition and diffusion values of human skin dermis $(44,57)$ were collected to validate the modified equations along with the other models of Bunge (53), Ibrahim (58), and Kretsos (44). Figure 5 shows the observed data of $K_{\text {dew }}$ and $D_{d e}$ against predicted values. Bunge model (Eq. 9) gave the worst fit to the observed $K_{\text {dew }}$ data with mean absolute percentage error $(M A P E)=225 \%$, whereas Ibrahim model (Eq. 10) and modified Ibrahim model (Eq. 11) gave similar predictions with $M A P E=46 \%$ for the Ibrahim model and $M A P E=57 \%$ for the modified Ibrahim model. For $D_{d e}$, the modified Kretsos model (Eq. 15) gave the best prediction with $M A P E=115 \%$, followed by the Kretsos model (Eq. 13) with $M A P E=131 \%$. The Bunge model (Eq. 12) still gave the worst predictions with the highest error with $M A P E=285 \%$.

The slight improvement of the modified equations of partition and diffusion in viable dermis and dermis could be the way the equations are derived. The Bunge equations (Eqs. 9 and 12) were statistical correlations of bulk property. The Ibrahim equation (Eq. 10) and the Kretsos equation (Eq. 13) considering the multiphase nature of viable epidermis and dermis, but the assigned lipid content is too low. Based on the improved estimation of lipid content and partition property, the modified Ibrahim model (Eq. 11) and the modified Kretsos model (Eq. 15) were developed, leading to slight improvement.

Table IV Comparison of the Observed and Predicted Disposition Data of the Test Chemicals: Determined Coefficient $\left(r^{2}\right)$ and Relative Root Mean Squared Error (RMSE)

\begin{tabular}{llc}
\hline Test chemical & $r^{2}$ & Relative RMSE \\
\hline I,4-dihydroquinone & 0.97 & 0.52 \\
benzaldehyde & 0.89 & 0.64 \\
3,4-dihydrocoumarin & 0.98 & 0.96 \\
4-ethylresorcinol & 0.94 & 0.50 \\
cinnamic aldehyde & 0.98 & 0.54 \\
6-methylcoumarin & 0.90 & 1.17 \\
cinnamic alcohol & 0.97 & 0.72 \\
2,4-dinitrochlorobenzene & 0.96 & 0.42 \\
phenylbenzoate & 0.05 & 2.54 \\
a-hexylcinnamic aldehyde & 0.02 & 47.63 \\
I-bromododecane & 0.55 & 0.87 \\
I-bromohexadecane & 0.84 & 1.16 \\
\hline
\end{tabular}




\section{Simulation of Chemical Absorption and Disposition Kinetics in Skin Layers}

Simulated data of solute absorption and disposition kinetics in different skin layers are compared with the experimental data. For chemicals with different concentrations, the average mass percentages of applied dose are used. The model performance for each chemical is evaluated by the following parameters: $r^{2}$ (the coefficient of determination) and RMSE (root mean squared error). To ensure different skin layers with

a

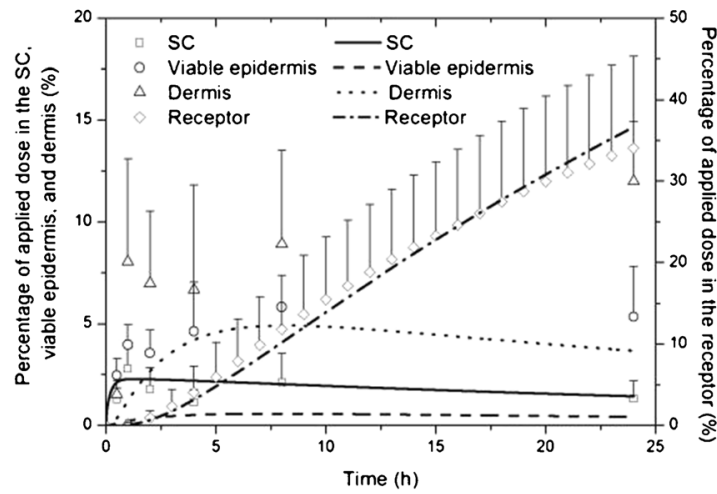

C

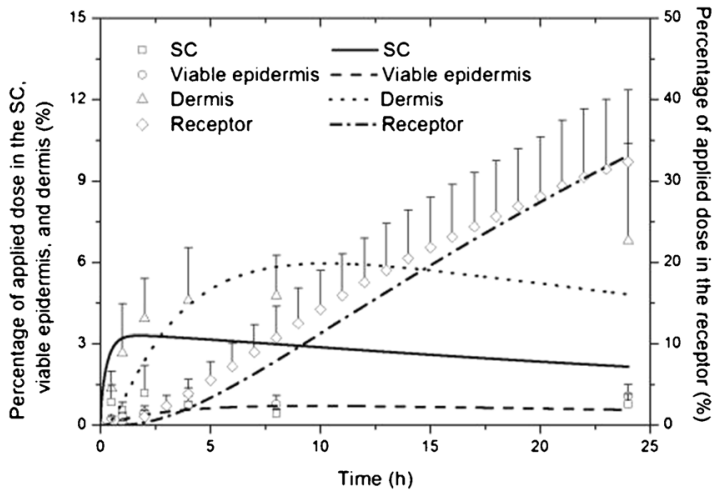

e

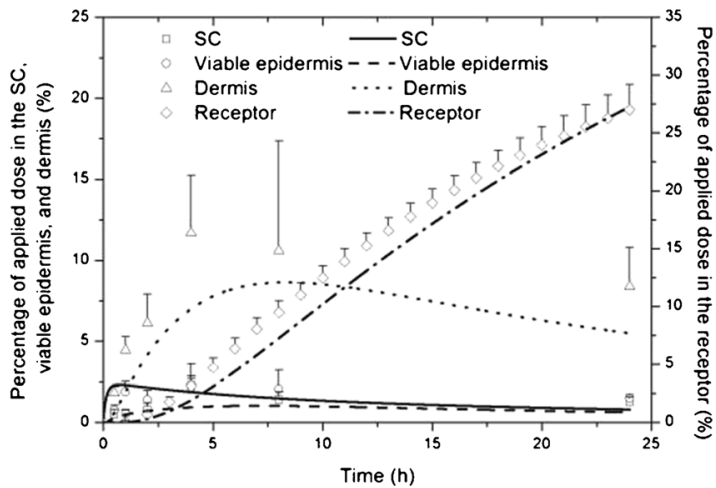

comparable weight coefficient, the relative $R M S E$ is calculated as follows:

Relative $R M S E=\frac{1}{4} \times \sum_{j=1}^{4} \sqrt{\frac{1}{n_{j}} \sum_{i=1}^{n_{j}}\left[\left(Y_{i}^{o j}-Y_{i}^{p j}\right) / \bar{\Upsilon}_{i}^{o j}\right]^{2}}$

where $j=1,2,3$, and 4 denotes the $\mathrm{SC}$, viable, dermis, and receptor, respectviely; $Y_{i}^{o j}$ are the observed mass percentages of applied dose in the $\mathrm{SC}$, viable epidermis, dermis, and

b

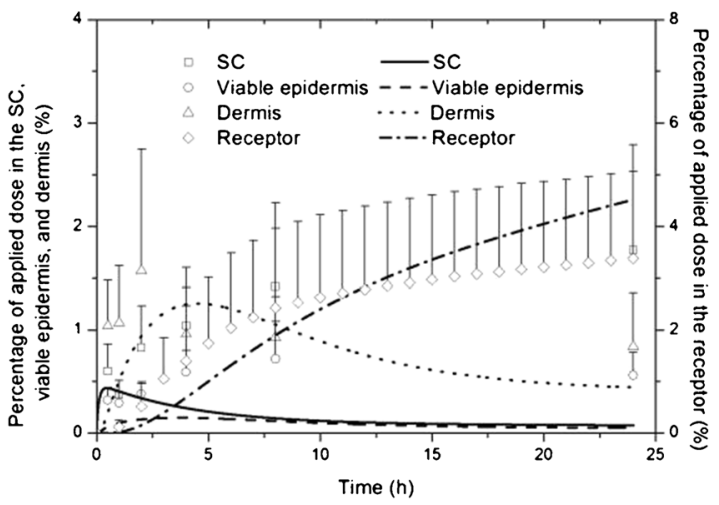

d

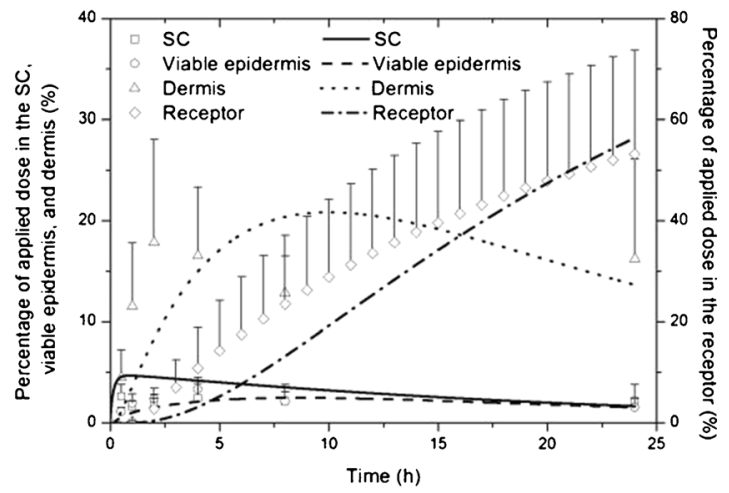

f

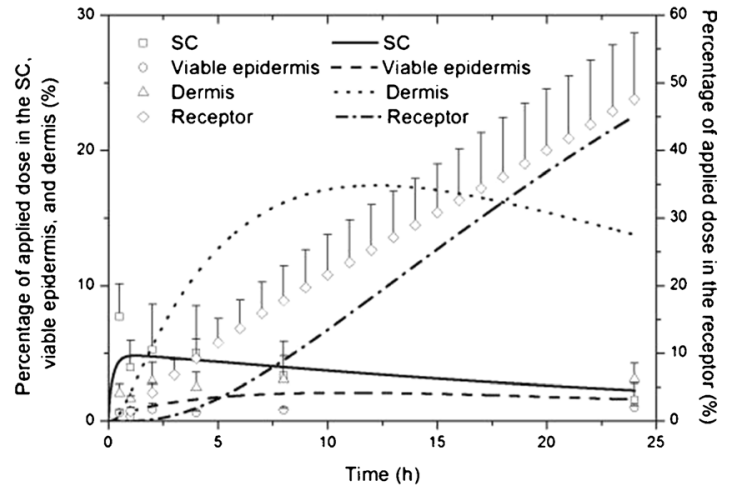

Fig. 6 Model prediction (lines) compared with observed data (points) of the typical chemicals distributed in the SC, viable epidermis, dermis, and receptor fluid: (a) I,4-dihydroquinone, (b) benzaldehyde, (c) 3,4-dihydrocoumarin, (d) 4-ethylresorcinol, (e) cinnamic aldehyde, (f) 6-methylcoumarin, (g) cinnamyl alcohol, (h) 2,4-dinitrochlorobenzene, (i) phenylbenzoate, (j) alpha-hexylcinnamic aldehyde, (k) I-bromododecane, (I) I-bromohexadecane. 
receptor, respectively; ${ }_{i}^{o j}$ are the mean values of $Y_{i}^{o j} ; Y_{i}^{p j}$ are the predicted mass percentages of applied dose in the SC, viable epidermis, dermis, and receptor, respectively; $n_{j}$ are the sample number in the $\mathrm{SC}$, viable epidermis, dermis, and receptor, respectively.

The $R^{2}$ and relative $R M S E$ values were listed in Table IV. Comparisons of observed and predicted amount of permeated into the $\mathrm{SC}$, viable epidermis, dermis and receptor fluid are shown in Fig. 6 for 12 tested chemicals. For most tested chemicals current model gave good correlations with $R^{2}>$
0.80 and relative $R M S E<1.20$. It should be noted that the correlations for $\alpha$-hexylcinnamic aldehyde and phenylbenzoate were much worse than those of the other tested compounds. For $\alpha$-hexylcinnamic aldehyde, the predicted errors mainly existed in the data of the $\mathrm{SC}$ and dermis layers. The experimental data in the $\mathrm{SC}$ and dermis layers were the highest and lowest among the tested chemicals, respectively. This was unexpected because the $\log K_{\text {ow }}(=4.82)$ and $M W(=216.33)$ of $\alpha$-hexylcinnamic aldehyde were in the medium range of the tested chemicals $\left(0.59 \leq \log K_{\text {ow }} \leq 8.54\right.$, g

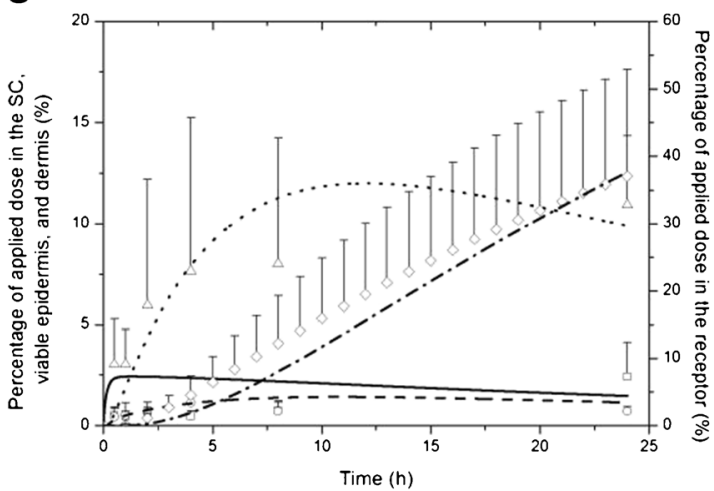

i

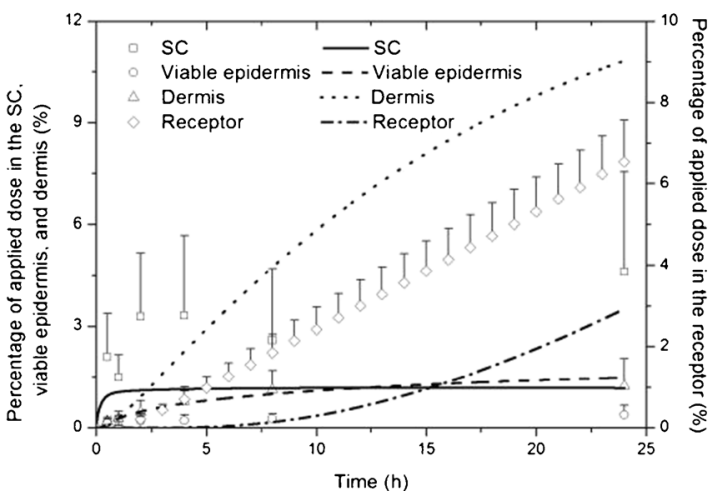

k

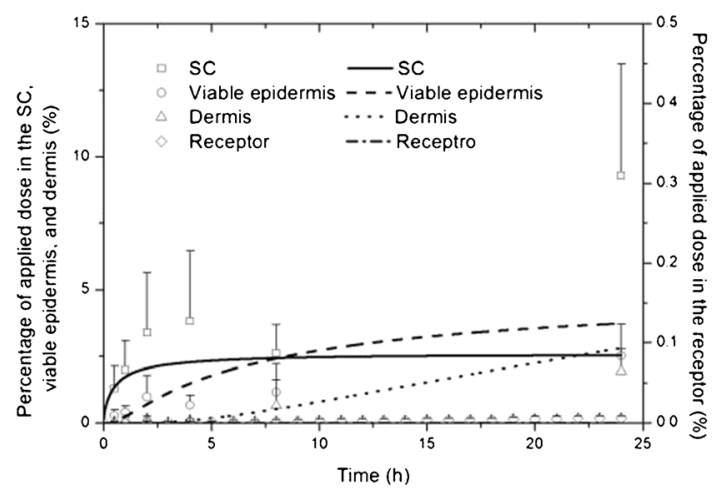

h

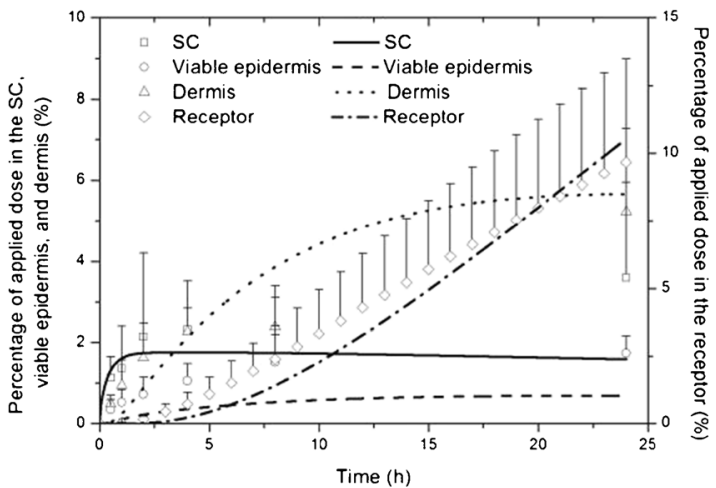

j

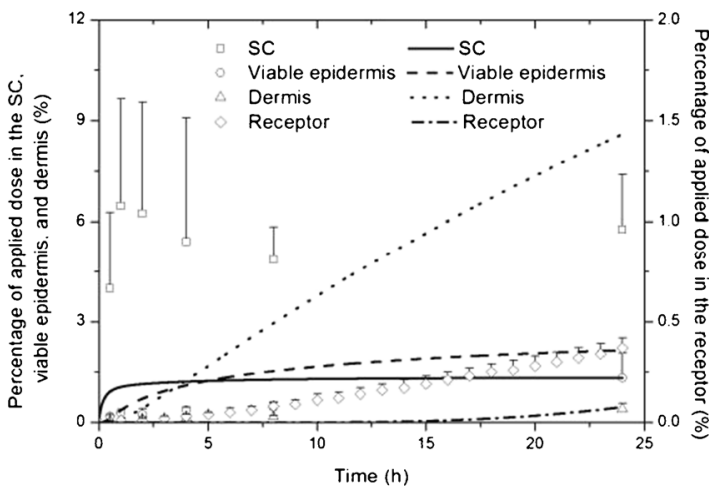

I

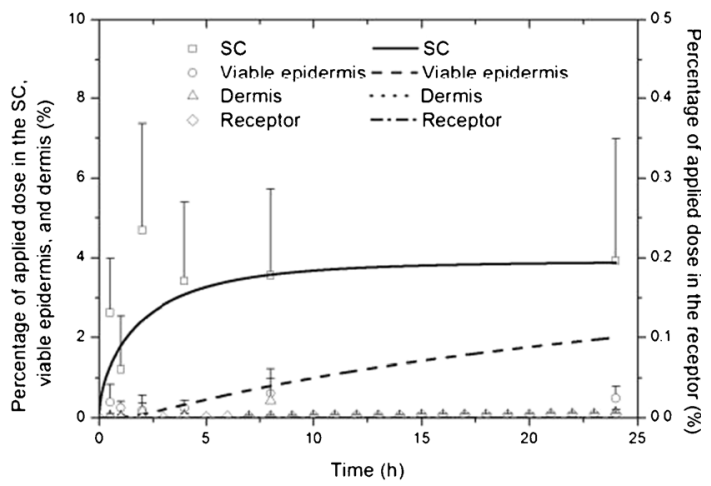

Fig. 6 continued. 
106.13 Da $\leq \mathrm{MW} \leq 305.35 \mathrm{Da}$ ). The simulations for the two chemicals were also a challenge to the compartment model of Davies et al. (2011), in which the three-skin compartment model with eight fitting parameters and two-skin compartment model with seven fitting parameters were applied.

a

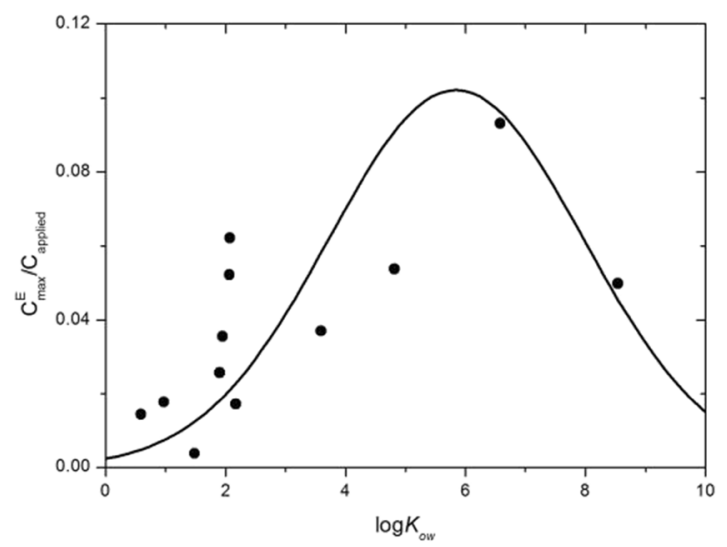

C

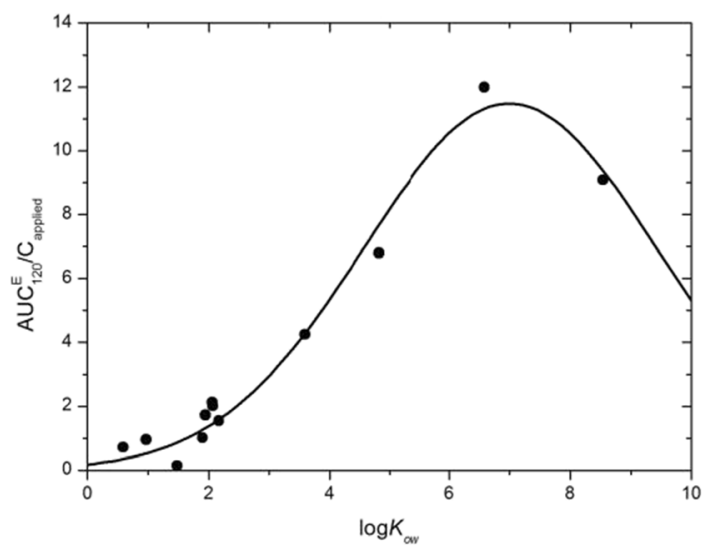

e

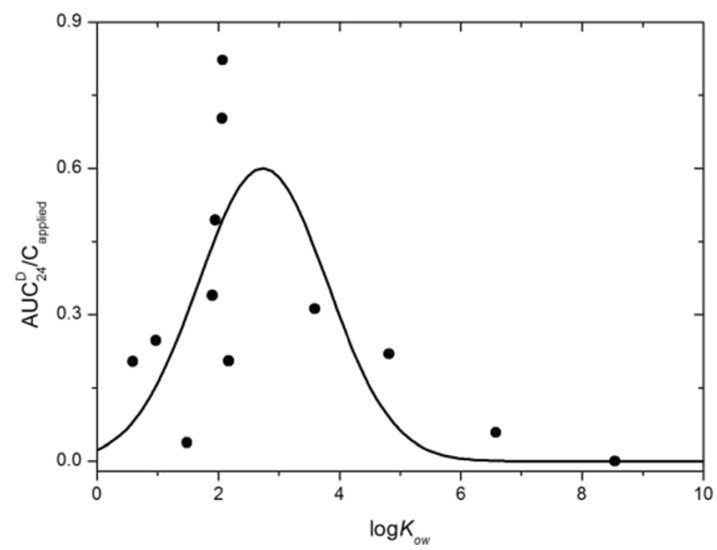

\section{DISCUSSION}

Benzaldehyde and cinnammic aldehyde have high volatility and significant loss of mass by evaporation. This resulted in reduced transdermal permeation. Only approximate $3.5 \%$ of

b

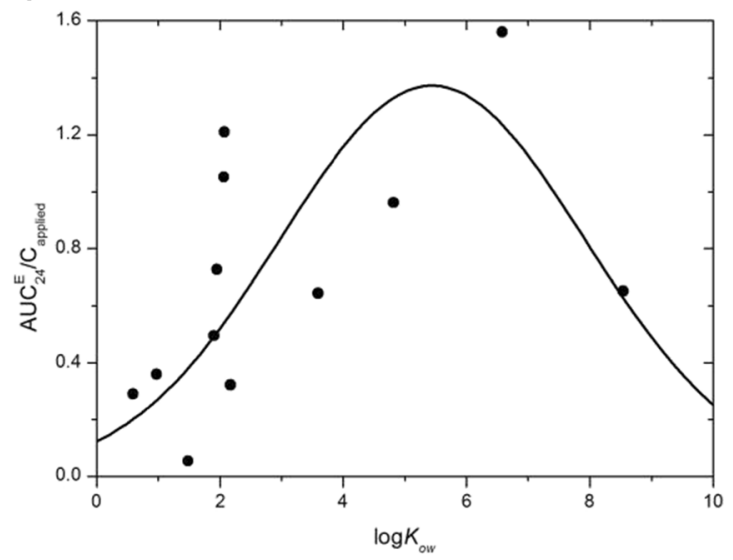

d

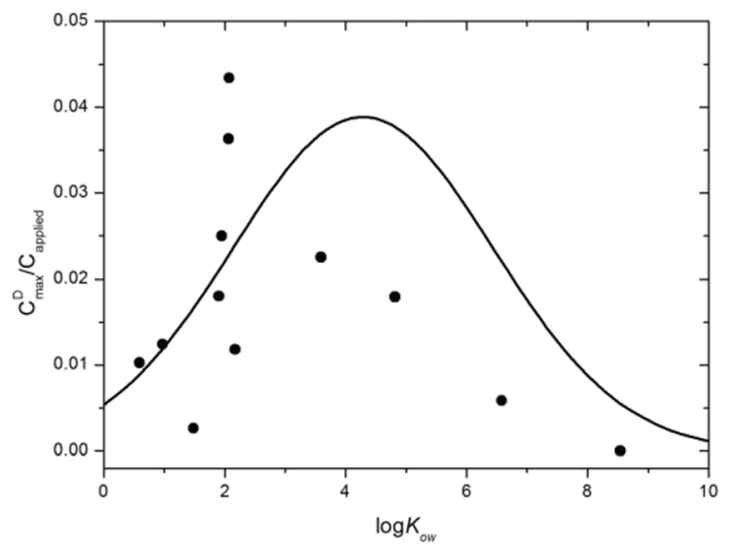

f

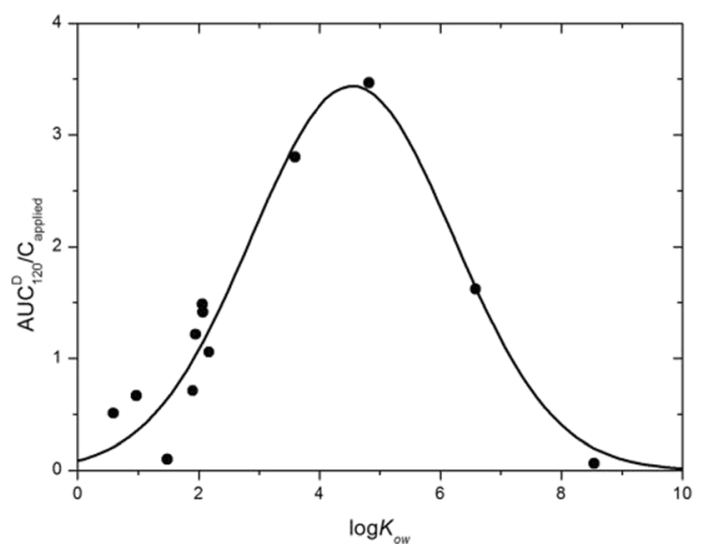

Fig. 7 The disposition kinetics parameters ( $C_{\max }$ and $\left.A \cup C\right)$ in the viable epidermis and dermis versus log $K_{\text {ow }}$ for chemicals: $(\mathbf{a}) C_{\max }^{E} / C_{\text {applied }}$ Vs log $K_{\text {ow }}(\mathbf{b}) A \cup C_{24}^{E} /$

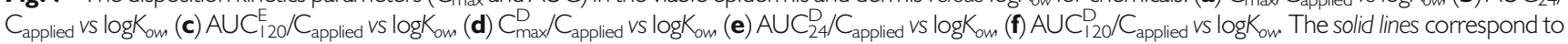
gaussian fits of the calculated disposition kinetics parameters with log $K_{\text {ow }}$ 
applied benzaldehyde permeated and absorbed by the skin after $24 \mathrm{~h}$. Cinnamic aldehyde had evaporative loss of about $40 \%$, but about $25 \%$ permeated into skin at the end of $24 \mathrm{~h}$. This is due to the fact that the transdermal permeation and absorption rate of cinnamic aldehyde outpaced its evaporation loss. Generally, small molecule with moderate hydrophobicity $\left(0.6<\log K_{\text {ow }}<2\right)$ and low volatility such as 3,4dihydrocoumarin has the highest transdermal permeation and absorption rate, whereas highly hydrophobic molecule such as 1-bromohexadecane $\left(\log K_{\text {ow }}=8.54\right)$ partitioned significantly into the SC but has limited amount penetrated across the skin after $24 \mathrm{~h}$. The aqueous continuous environment of the viable epidermis and dermis did not favor their deeper penetration and accumulation in the region. Clearly, as far as transdermal permeation and absorption in the dermis and viable epidermis is concerned, prediction of a single transdermal permeability parameter is not sufficient. The dynamic interaction that governs the disposition of solutes in different skin layers has to be fully taken into account. The extended general purpose computer model reported herein is able to predict the absorption and disposition kinetics in skin layers.

Two pharmacokinetic/toxicokinetic parameters can be used to characterize the disposition kinetics of chemicals in skin (8): the maximum concentration $\left(\mathbf{C}_{\max }\right)$ and the area under the curve (AUG). Here, the $\mathrm{C}_{\max }$ and $\mathrm{AUC}$ in the viable epidermis and dermis layers are obtained from the computer simulation and plotted in Fig. 7. Davies et al. (2011) investigated the spearman rank correlation coefficient between disposition kinetics parameters and $\log K_{\text {ow }}$ and found that the $\mathrm{C}_{\max }$ and $\mathrm{AUC}$ in the viable epidermis and dermis were not linearly correlated with $\log K_{\text {ow }}$. This is consistent with the observation in Fig. 7 that the disposition kinetics parameters are not shown to scale to hydrophobicity. The predicted $\mathrm{C}_{\max }$ and $\mathrm{AUC}$ in the viable epidermis and dermis initially increased with increasing hydrophobicity and reached maxima. As $K_{\text {ow }}$ further increases, $\mathrm{C}_{\max }$ and AUC decreased. This is consistent with the predicted behavior of transdermal permeation across the skin layers of viable epidermis and dermis discussed above: the aqueous continues environment of the viable epidermis and dermis did not favor the absorption of highly hydrophobic chemicals in the region. For risk assessment of chemical such as skin allergy and sensitization, the disposition kinetic parameters in the local regions of the affected cells are most relevant. Obtaining such locallized disposition kinetic parameters by experimental methods is apparently exceedingly difficult if not impossible. The approach presented in this study provides a valuable tool to access the required disposition kinetic parameters. With continued research on the fundamental properties of chemical partition, binding and mobility at sub-cellular level and molecular level, the predictive power and accuracy of such model can be further improved.

\section{CONCLUSIONS}

An extended model for closed-form in-silico prediction of percutaneous permeation, absorption and disposition kinetics of chemicals in skin layers of the SC, viable dermis and dermis has been developed. The extended model has been applied to predict transdermal absorption and disposition kinetics of 12 chemicals under in vitro diffusion cell conditions reported recently by Davies et al. (2011). The in-vitro experimental data of the chemicals provided a test of the predictive capability of the extended model. The results showed that the simulated data agreed well with the experimental data, with the exception of phenylbenzoate and $\alpha$-hexylcinnamic aldehyde. Detailed dermatopharmacokinetic information of chemical absorption and disposition in different skin layers including the viable epidermis and dermis $\left(\mathrm{C}_{\max }\right.$ and $\left.\mathrm{AUC}\right)$ are predicted for wide chemical space. It is shown that the effect of $K_{o w}$ on absorption and disposition kinetics in the viable epidermis and dermis is non-linear. Initially, as $K_{o w}$ increases, the amount of chemicals permeated across the skin as well as the disposition kinetic parameters in the viable epidermis and dermis increased. As $K_{o w}$ further increases, these parameters reached maxima and decreased, suggesting simple scaling law with hydrophobicity does not apply. The model presented in this study considers cellular heterogeneity of structure and composition and predicts local kinetics and disposition of chemicals in skin layers and hence provides an improved framework to support transdermal delivery of drugs and skincare actives as well as integrated risk assessment.

\section{ACKNOWLEDGMENTS AND DISCLOSURES}

This research is supported by Unilever R\&D Colworth UK, Program for New Century Excellent Talents in University (Project No. NCET-11-0477), and Program for Changjiang Scholars and Innovative Research Team in University (Project No. IRT1293). We wish to thank Cameron MacKay and Michael Davies for providing skin absorption data and helpful comments on the manuscript.

\section{REFERENCES}

1. Polat BE, Deen WM, Langer R, Blankschtein D. A physical mechanism to explain the delivery of chemical penetration enhancers into skin during transdermal sonophoresis - insight into the observed synergism. J Control Release. 2012;158:250-60.

2. Alexander A, Dwivedi S, Ajazuddin TK, Giri S, Saraf S, Saraf S, et al. Approaches for breaking the barriers of drug permeation through transdermal drug delivery. J Control Release. 2012;164: $26-40$.

3. Patzelt A, Lademann J, Richter H, Darvin ME, Schanzer S, Thiede $\mathrm{G}$, et al. In vivo investigations on the penetration of various oils and their influence on the skin barrier. Skin Res Technol. 2012;18:364-9. 
4. Knaak J, Dary C, Zhang X, Gerlach R, Tornero-Velez R, Chang D, et al. Parameters for pyrethroid insecticide QSAR and PBPK/PD models for human risk assessment. In: Whitacre DM, editor. Reviews of environmental contamination and toxicology, vol. 219. New York: Springer; 2012. p. 1-114.

5. Boonen J, Malysheva SV, Taevernier L, Diana Di Mavungu J, De Saeger S, De Spiegeleer B. Human skin penetration of selected model mycotoxins. Toxicology. 2012;301:21-32.

6. Louisse J, de Jong E, van de Sandt JJM, Blaauboer BJ, Woutersen RA, Piersma AH, et al. The use of in vitro toxicity data and physiologically based kinetic modeling to predict dose-response curves for in vivo developmental toxicity of glycol ethers in rat and man. Toxicol Sci. 2010;118:470-84.

7. MacKay C, Davies M, Summerfield V, Maxwell G. From pathways to people: applying the adverse outcome pathway (AOP) for skin sensitization to risk assessment. ALTEX: Alternatives to Animal Experiments. 2013. doi: pii: S1868696X1301251X.

8. Basketter D, Pease G, Kasting G, Kimber I, Casati S, Cronin M, et al. Skin sensitisation and epidermal disposition: the relevance of epidermal disposition for sensitisation hazard identification and risk assessment. The report and recommendations of ECVAM workshop 59. Altern Lab Anim. 2007;35:137-54.

9. Pendlington RU, Minter HJ, Stupart L, MacKay C, Roper CS, Sanders DJ, et al. Development of a modified in vitro skin absorption method to study the epidermal/dermal disposition of a contact allergen in human skin. Cutan Ocul Toxicol. 2008;27:283-94.

10. Abrahamand MH, Martins F. Human skin permeation and partition: general linear free-energy relationship analyses. J Pharm Sci. 2004;93:1508-23.

11. Moss GP, Dearden JC, Patel H, Cronin MTD. Quantitative structure-permeability relationships (qsprs) for percutaneous absorption. Toxicol in Vitro. 2002;16:299-317.

12. Mitragotri S. Modeling skin permeability to hydrophilic and hydrophobic solutes based on four permeation pathways. J Control Release. 2003;86:69-92.

13. Pottsand RO, Guy RH. Predicting skin permeability. Pharm Res. 1992;9:663-9

14. Chen LJ, Lian GP, Han LJ. Use of "bricks and mortar" model to predict transdermal permeation: model development and initial validation. Ind Eng Chem Res. 2008;47:6465-72.

15. Davies M, Pendlington RU, Page L, Roper CS, Sanders DJ, Bourner $\mathrm{C}$, et al. Determining epidermal disposition kinetics for use in an integrated nonanimal approach to skin sensitization risk assessment. Toxicol Sci. 2011;119:308-18.

16. van der Merwe D, Brooks JD, Gehring R, Baynes RE, MonteiroRiviere NA, Riviere JE. A physiologically based pharmacokinetic model of organophosphate dermal absorption. Toxicol Sci. 2006;89:188-204.

17. Polak S, Ghobadi C, Mishra H, Ahamadi M, Patel N, Jamei M, et al. Prediction of concentration-time profile and its inter-individual variability following the dermal drug absorption. J Pharm Sci. 2012;101: 2584-95.

18. McCarleyand KD, Bunge AL. Pharmacokinetic models of dermal absorption. J Pharm Sci. 2001;90:1699-719.

19. Poet TS, Weitz KK, Gies RA, Edwards JA, Thrall KD, Corley RA, et al. PBPK modeling of the percutaneous absorption of perchloroethylene from a soil matrix in rats and humans. Toxicol Sci. 2002;67:17-31.

20. Wang TF, Kasting GB, Nitsche JM. A multiphase microscopic diffusion model for stratum corneum permeability. I. Formulation, solution, and illustrative results for representative compounds. J Pharm Sci. 2006;95:620-48.

21. Anissimov YG, Jepps OG, Dancik Y, Roberts MS. Mathematical and pharmacokinetic modelling of epidermal and dermal transport processes. Adv Drug Deliv Rev. 2013;65:169-90.

22. Chen L, Han L, Lian G. Recent advances in predicting skin permeability of hydrophilic solutes. Adv Drug Deliv Rev. 2013;65:295-305.
23. Dancik Y, Miller MA, Jaworska J, Kasting GB. Design and performance of a spreadsheet-based model for estimating bioavailability of chemicals from dermal exposure. Adv Drug Deliv Rev. 2013;65: 221-36.

24. Fraschand HF, Barbero AM. Application of numerical methods for diffusion-based modeling of skin permeation. Adv Drug Deliv Rev. 2013;65:208-20.

25. Gratieriand T, Kalia YN. Mathematical models to describe iontophoretic transport in vitro and in vivo and the effect of current application on the skin barrier. Adv Drug Deliv Rev. 2013;65: 315-29.

26. Hansen S, Lehr C-M, Schaefer UF. Improved input parameters for diffusion models of skin absorption. Adv Drug Deliv Rev. 2013;65: $251-64$.

27. Jepps OG, Dancik Y, Anissimov YG, Roberts MS. Modeling the human skin barrier - towards a better understanding of dermal absorption. Adv Drug Deliv Rev. 2013;65:152-68.

28. Karadzovska D, Brooks JD, Monteiro-Riviere NA, Riviere JE. Predicting skin permeability from complex vehicles. Adv Drug Deliv Rev. 2013;65:265-77.

29. Naegel A, Heisig M, Wittum G. Detailed modeling of skin penetration - an overview. Adv Drug Deliv Rev. 2013;65:191-207.

30. Notmanand R, Anwar J. Breaching the skin barrier — insights from molecular simulation of model membranes. Adv Drug Deliv Rev. 2013;65:237-50.

31. Rauma M, Boman A, Johanson G. Predicting the absorption of chemical vapours. Adv Drug Deliv Rev. 2013;65:306-14.

32. Selzer D, Abdel-Mottaleb MMA, Hahn T, Schaefer UF, Neumann D. Finite and infinite dosing: difficulties in measurements, evaluations and predictions. Adv Drug Deliv Rev. 2013;65:278-94.

33. Lian GP, Chen LJ, Han LJ. An evaluation of mathematical models for predicting skin permeability. J Pharm Sci. 2008;97: 584-98.

34. Mitragotri S, Anissimov YG, Bunge AL, Frasch HF, Guy RH, Hadgraft $\mathrm{J}$, et al. Mathematical models of skin permeability: an overview. Int J Pharm. 201 1;418:115-29.

35. Wang TF, Kasting GB, Nitsche JM. A multiphase microscopic diffusion model for stratum corneum permeability. II. Estimation of physicochemical parameters and application to a large permeability database. J Pharm Sci. 2007;96:3024-51.

36. Anissimovand YG, Roberts MS. Modelling dermal drug distribution after topical application in human. Pharm Res Dordr. 2011;28: 2119-29.

37. Naegel A, Hansen S, Neumann D, Lehr CM, Schaefer UF, Wittum $\mathrm{G}$, et al. In-silico model of skin penetration based on experimentally determined input parameters. Part II. Mathematical modelling of invitro diffusion experiments. Identification of critical input parameters. Eur J Pharm Biopharm. 2008;68:368-79.

38. Selzer D, Hahn T, Naegel A, Heisig M, Kostka KH, Lehr CM, et al. Finite dose skin mass balance including the lateral part: comparison between experiment, pharmacokinetic modeling and diffusion models. J Control Release. 2013;165:119-28.

39. Hansen S, Henning A, Naegel A, Heisig M, Wittum G, Neumann D, et al. In-silico model of skin penetration based on experimentally determined input parameters. Part I. Experimental determination of partition and diffusion coefficients. Eur J Pharm Biopharm. 2008;68:352-67.

40. Hansch G, Leo A, Hoekman D. Exploring QSAR: hydrophobic, electronic, and steric constants. Washington: American Chemical Society; 1995

41. Debnath AK, Decompadre RLL, Debnath G, Shusterman AJ, Hansch C. Structure activity relationship of mutagenic aromatic and heteroaromatic nitro-compounds - correlation with molecularorbital energies and hydrophobicity. J Med Chem. 1991;34:786-97.

42. Odland G, editor. Structure of the skin. Oxford: Oxford University Press; 1991. 
43. Williams FM. In vitro studies - how good are they at replacing in viwo studies for measurement of skin absorption? Environ Toxicol Pharmacol. 2006;21:199-203.

44. Kretsos K, Miller M, Zamora-Estrada G, Kasting GB. Partitioning, diffusivity and clearance of skin permeants in mammalian dermis. Int J Pharm. 2008;346:64-79.

45. Abramovicand H, Klofutar C. The temperature dependence of dynamic viscosity for some vegetable oils. Acta Chim Slov. 1998;45:69-77.

46. Einstein A. Uber die von der molekular-kineticshen theorie der warme geforderte bewegung von in ruhenden flussigkeiten suspendierten teilchen. Ann Phys. 1905;17:549-60.

47. Nitsche JM, Wang TF, Kasting GB. A two-phase analysis of solute partitioning into the stratum corneum. J Pharm Sci. 2006;95:649-66.

48. Wang LM, Chen LJ, Lian GP, Han LJ. Determination of partition and binding properties of solutes to stratum corneum. Int J Pharm. 2010;398:114-22.

49. Chen LJ, Lian GP, Han LJ. Modeling transdermal permeation. Part I. Predicting skin permeability of both hydrophobic and hydrophilic solutes. AICHE J. 2010;56:1136-46.

50. Jacksonand GW, James DG. The permeability of fibrous porous media. Can J Chem Eng. 1986;64:362-74.

51. Kasting GB, Barai ND, Wang TF, Nitsche JM. Mobility of water in human stratum corneum. J Pharm Sci. 2003;92:2326-40.
52. Kasting GB, Miller MA, Nitsche JM. Absorption and evaporation of volatile compounds applied to skin. In: Waltersand KA, Roberts MS, editors. Dermatologic, cosmeceutic, and cosmetic development. Boca Raton: CRC Press; 2007. p. 385-99.

53. Bungeand AL, Gleek RL. A new method for estimating dermal absorption from chemical exposure: 2 Effect of molecular weight and octanol-water partitioning. Pharm Res. 1995;12:88-95.

54. Yamazakiand K, Kanaoka M. Computational prediction of the plasma protein-binding percent of diverse pharmaceutical compounds. J Pharm Sci. 2004;93:1480-94.

55. Gong M, Zhang Y, Weschler CJ. Predicting dermal absorption of gas-phase chemicals: transient model development, evaluation, and application. Indoor Air. 2014;24:292-306.

56. Frasch HF, Dotson GS, Bunge AL, Chen CP, Cherrie JW, Kasting $\mathrm{GB}$, et al. Analysis of finite dose dermal absorption data: implications for dermal exposure assessment. J Expo Sci Environ Epidemiol. 2014;24:65-73.

57. Magnusson BM, Cross SE, Winckle G, Roberts MS. Percutaneous absorption of steroids: determination of in vitro permeability and tissue reservoir characteristics in human skin layers. Skin Pharmacol Physiol. 2006; 19:336-42.

58. Ibrahim R, Nitsche JM, Kasting GB. Dermal clearance model for epidermal bioavailability calculations. J Pharm Sci. 2012;101:2094 108. 